\title{
Making it All Count: A Cross-Disciplinary Collaboration Model Incorporating Scholarship, Creative Activity, and Student Engagement
}

\author{
Rocky Dailey, EdD \\ Assistant Professor, Department of Journalism and Mass Communication \\ South Dakota State University \\ Melissa Hauschild-Mork, EdD \\ Assistant Professor, Department of Communication Studies and Theatre \\ South Dakota State University
}

This study takes a grounded theory approach as a basis for a case study examining a crossdisciplinary artistic and academic collaborative project involving faculty from the areas of English, music, dance, theatre, design, and visual journalism resulting in the creation of research, scholarly, and creative activity that fosters student engagement with feedback, reflection, and mentorship. An emergent conceptual model of artistic and academic collaboration was developed featuring a combination of collaborative partnership, creative process, and product dissemination with feedback and reflection leading to greater collaborative partnership as well as a new community of practice for cross-disciplinary collaboration.

One of the challenges academics face is balancing the demands of teaching, scholarship, and service, as those aspects are often isolated from each other. As scholarship must be peer-reviewed and disseminated, the work that goes into it is only recognized if it finds an audience. A faculty member could spend months or even years on a project that does not meet these criteria. Further, teaching and service often have little interaction with scholarly or creative endeavors, especially to faculty teaching general humanities-based courses to large sections.

One response to this challenge is to integrate the roles of teaching, scholarship, and service. As stated by Dr. Kenneth P. Ruscio (2013), President of Washington and Lee University, "The dash between teacher and scholar is meant to be a link, not a line of demarcation" (p. 27). This is one of the reasons why the Scholarship of Teaching and Learning (SoTL) exists: to better integrate the duties of academics in those disciplines that do not have a clear link between teaching and scholarly or creative work (Huber, 2004).

Collaboration among academics and artists is not uncommon (Blom, Bennett, \& Wright, 2011; Neuschäfer, 2008). The synergy created by collaboration can facilitate stronger works by calling upon the unique skills and knowledge of all involved. Such synergy can come from collaboration across disciplines; however, such collaboration is less common in the arts and humanities than in the sciences. Including approaches from the artistic community creates a form of collaboration that brings together a variety of academics and artists. Such a unique collaboration would bring with it unique challenges, so it is worth exploring ways to satisfy the goals of all involved.

This study takes a grounded theory approach (Charmaz, 2003; Geertz, 1973; Strauss \& Corbin, 1998) as the basis for a case study examining a cross-disciplinary artistic and academic collaborative project involving faculty from the areas of English, 
music, dance, theatre, design, and visual journalism at South Dakota State University (SDSU) in Brookings, South Dakota. SDSU is a four-year public upper Midwest land grant university with a student population of approximately 12,500 and a basic Carnegie classification of a doctoral university with higher research activity and undergraduate instructional programs featuring professions plus arts and sciences. The Harvey Dunn Feminine Images Collaborative Project created research, scholarly, and creative activity to benefit all involved disciplines while fostering student engagement with feedback, reflection, and mentorship. Through

The complete collaborative project was presented as a multi-dimensional performance... examining their process, the collaborators developed models featuring artistic and academic as well as student and faculty collaboration. The artistic project initially developed from an idea among humanities faculty to feature the work of a well-known American painter Harvey Dunn (1934), whose work was displayed on campus at the South Dakota Art Museum.

The project began in 2009, with the first step being a series of poems inspired by the artist's work composed by SDSU English Lecturer Darla Bielfeldt, who then sought out collaboration with SDSU Dance Coordinator and Assistant Professor Melissa Hauschild-Mork and SDSU Music Associate Professor Aaron Ragsdale to create performance work to complement the poetry and paintings. Graphic Design Professor Cable Hardin and Journalism and Mass Communication Professor Rocky Dailey were then brought in to develop visual arts to go along with the other elements. The complete collaborative project was presented as a multi-dimensional performance with further collaboration from SDSU Theatre Professors Billy Wilburn, Corey Shelsta, and Lynn Verschoor of the South Dakota Art Museum as well as the SDSU Yeager Media Center (Hauschild-Mork, Bielfeldt, Ragsdale, Dailey, \& Hardin, 2015). Related projects include a video production featuring the performance and a documentary focusing on the collaborative process.

The goals of this collaborative project included contributing to the lifelong development of engaged student collaborators by fostering opportunities to work collaboratively with faculty mentors to encourage cross-disciplinary artistic endeavors as well as the professional, scholarly, and creative growth of collaborating faculty by facilitating creativity and artistic excellence among collaborators, which creates opportunities for ongoing research and presentations.

Through this project, an emergent conceptual model of artistic and academic collaboration was developed. This featured a combination of collaborative partnership, creative process, and product dissemination with informed feedback and reflection. This combination then leads to another level of collaboration, starting the model cycle over again while building towards further creative and scholarly work. This leads to the development of a new community of practice for cross-disciplinary collaboration and opportunities in teaching and learning by fostering student engagement with feedback, reflection, and mentorship towards producing a product that relates to experiential teaching and learning as well as research in student engagement. 


\section{Literature Review}

Collaboration defined. The first step in creating a collaboration model is to define what collaboration is. In a review of collaboration literature, Patel, Pettit, and Wilson (2012) define collaboration as involving two or more people engaged in interaction with each other, within a single episode or series of episodes, working towards common goals. In another analysis of collaboration research, Mattessich and Monsey (1992) define collaboration as a more rigorous type of cooperation and coordination, with relationships being more formal and compatible with each collaborator having authority over their particular contribution to the whole. This relates well to work by artist Francois Deck (2004), who developed the idea of competence-crossing, meaning the individual artist or contributor keeps their artistic autonomy while still contributing to the whole.

Collaboration and the academic. French anthropologist Claude Lévi-Strauss (1973) discussed one aspect of artistic collaboration as being founded upon mutual interest. The interest for humanities faculty lies both in the area of creating peerreviewed and disseminated scholarly and creative work and also to meet their own artistic aspirations. Research by Landry, Traore, and Godin (1996) indicates that collaboration among academics may increase productivity even across disciplines and should be encouraged at all levels. A review of the literature by Alberto and Herth (2009) suggests that the roles of research, scholarship, and service can be mutually supported through effective collaboration among academics.

Work by Burbank and Kauchak (2003) promotes the idea of collaborative action research, which combines groups of teachers in the design, implementation, and evaluation of action research projects as a mechanism for professional development. While action research is research that is either developed to solve an immediate problem or as a way to develop a community of practice, it illustrates the potential collaboration has to create works that provide professional development opportunities for those involved. This connects to the scholarship of teaching and learning by working to develop a new pedagogy through a community of practice by incorporating both self-evaluation and reflection on the effectiveness of educational design and implementation.

Models of collaboration. Collaboration can take many forms. In terms of collaboration models, the bulk of published research revolves around the development of systems and technology to support collaboration. One such model that has been used in the development of software designed to improve collaboration is the $3 \mathrm{C}$ model by Ellis, Gibbs, and Rein (1991). This model (Figure 1) has been used and adapted frequently as a way to classify collaborative systems, as done by Borghoff and Schlichter (2000) as well as Fuks, Rapaso, Gerosa, and Lucena (2005). 


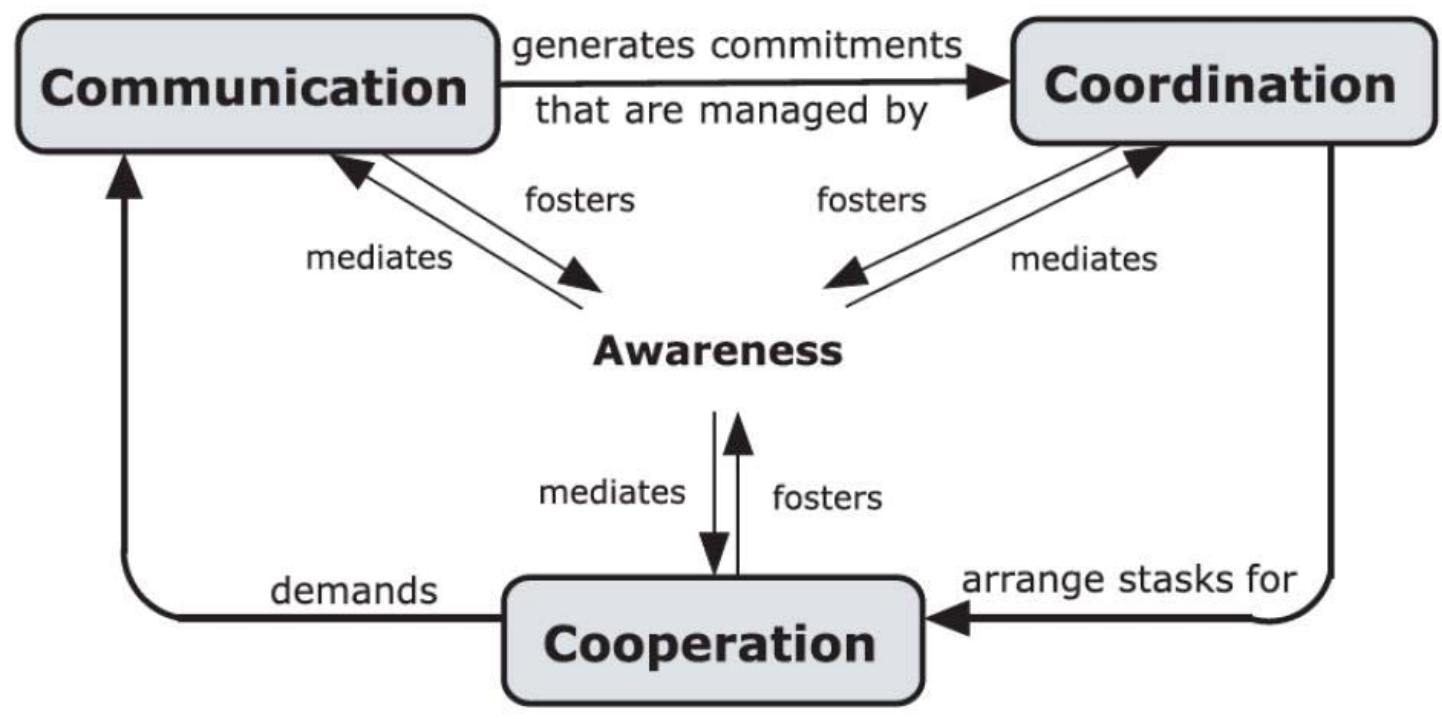

Figure 1.3C Collaboration Model

Research dealing specifically with creative collaboration across disciplines by Mamykina, Candy, and Edmonds (2002) defined collaboration as consisting of creative conceptualization, realization or implementation, and evaluation, with each collaborator adopting a specific role based on their area of contribution. The partnership model with artistic control developed by Candy and Edmonds (2002) brings collaborators together to fill a specific role while the entire group benefits from what is produced. For example, one collaborator may have the main responsibility of creating assessment instruments such as rubrics or assignments based on their skill in that area. These measures benefit the entire group, yet one contributor took the lead in that area. This collaboration is fueled by extensive discussions to create a common understanding of the artistic intention and what roles are necessary. While all collaborators are part of all key creative discussion, control over specific areas remains with whoever holds that role. Participants are distinguished by the general roles of artists and art-technologists in this model. In Figure 2, the darker shades indicate a strong level of activity where lighter shades indicate a significant, but not leading, role.

\begin{tabular}{|l|l|l|}
\hline & Artist & Art-Tech \\
\hline Concept & & \\
\hline Construction & & \\
\hline Evaluation & & \\
\hline
\end{tabular}

Figure 2. Candy \& Edmonds Collaboration Partnership Model

In complex artistic endeavors, collaboration is often necessary to meet the demands of the project. It can also help to get the creative process going in new and 
exciting ways. In Vera John-Steiner's (2000) book Creative Collaboration, she explores artistic collaboration. John-Steiner suggests that artists begin collaboration in the hope that collaborators complement their own contribution, but then evolve into an integrative collaboration that both transforms their work and their personal lives.

One challenge to the idea of collaboration among academics is loss of autonomy. A cross-discipline collaborative model by Jones (2001) addresses the autonomy issue by giving the collaborators control over their specific contributions while maintaining continuous discussion on project goals (Figure 3). While the model is designed with course development collaboration in mind, there are elements applicable to other forms of cross-disciplinary collaboration.

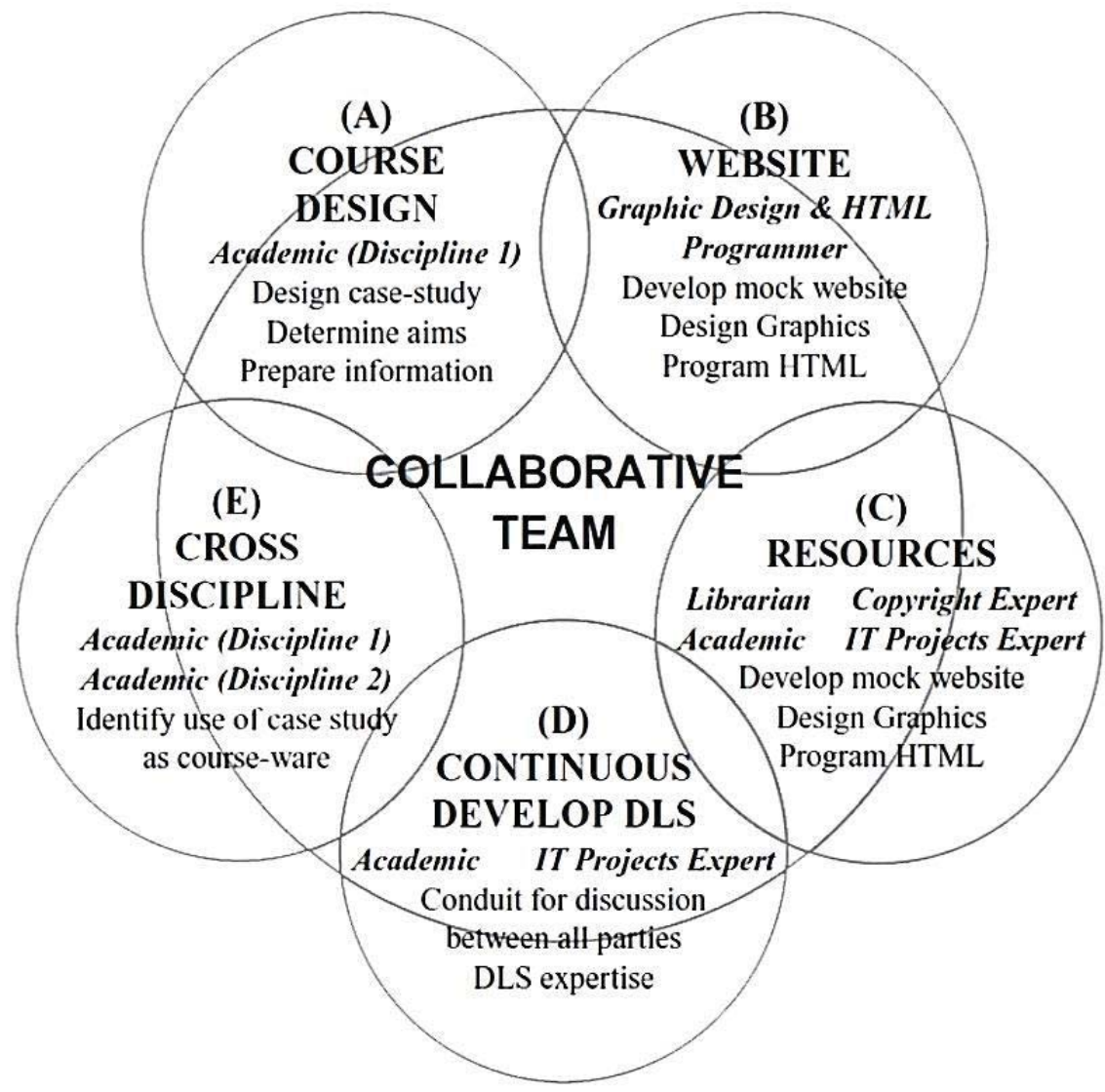

Figure 3. Jones Model for Cross-Functional and Cross-Disciplinary Collaboration

Within the area of general education collaboration, the model developed by Simpson and Myles (1990) has a strong focus on student engagement and learning. Originally developed to help teach disabled students, the model is based on flexible departmentalization, program ownership, identification and development of supportive attitudes, student assessment as a measure of program effectiveness, and classroom modifications that support mainstreaming (Figure 4). This model differs from the others by recognizing the importance of flexibility and attitude while still recognizing the importance of individuals taking more of a lead in aspects they have more experience in. 


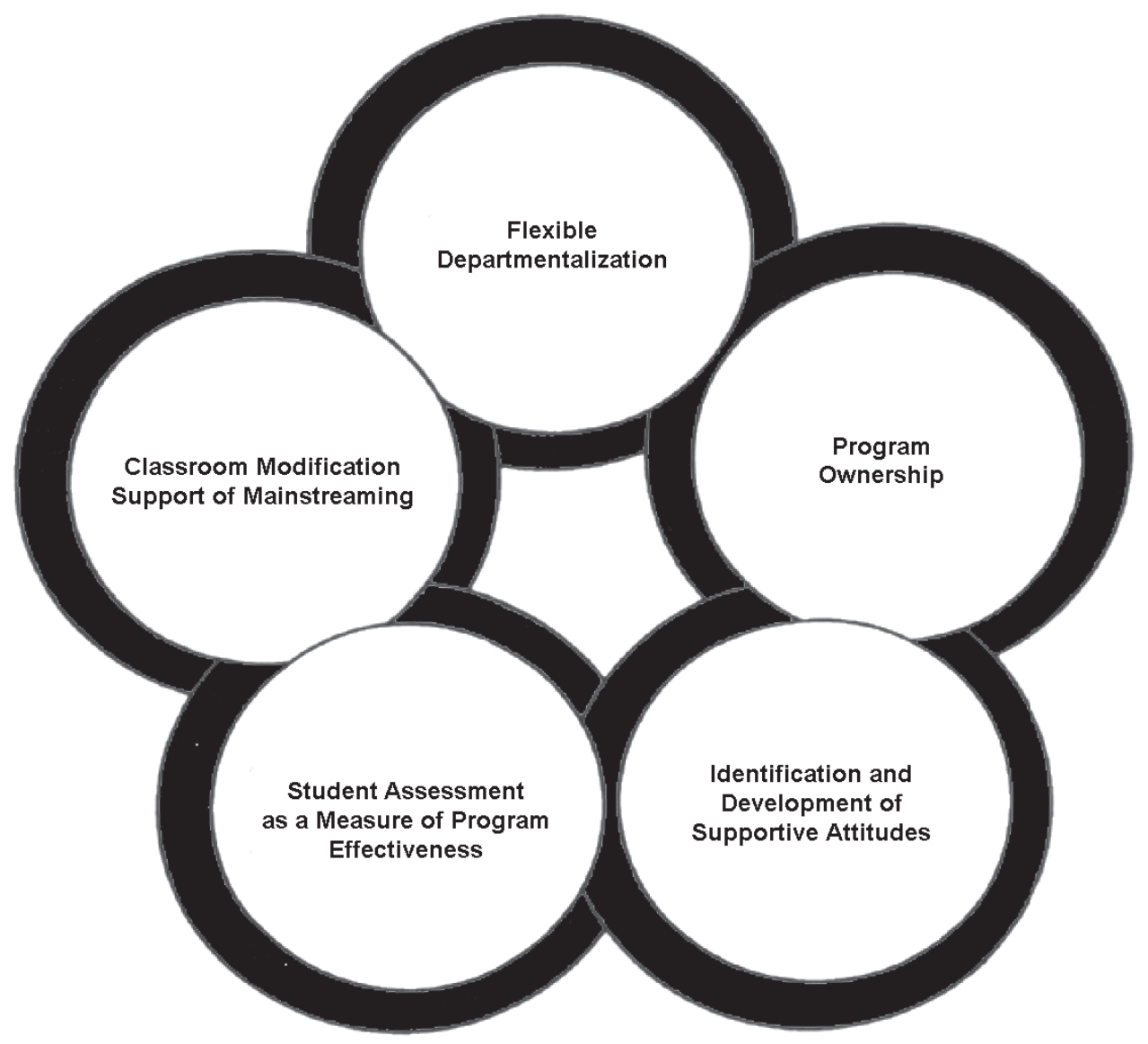

Figure 4. General Education Collaboration Model

All of these models focus on the need for continuous communication and reflection as well as well-defined roles, yet there is no modeling of how the work produced may foster further collaboration and how the fruits of that work can extend beyond the initial project.

\section{The Harvey Dunn Feminine Images Cross-Disciplinary Artistic and Academic Collaborative Project}

The intention of the project was for audience members to experience Harvey Dunn's (1934) paintings through the creative vision of faculty, staff, and students from different disciplines. The performance piece used shared artistic language to capture the human condition. Audience members engaged in each of the paintings as an integrated member of the performance experience; images, textures, sound, movement, and visual art unfolded in a seamless integration around them.

The performance included five trans-artistic collaborations: (a) MusicTextural sound-score derived from an original music composition, choral performance, and the recorded natural sounds of the prairie landscape; (b) Dance-Live and recorded movement to include an original dance composition; (c) Lyrical languageEkphrastic poetry (portrays the paintings in words) and language from Harvey Dunn's (1934) art instruction book, Evening in the Classroom; (d) Visual arts - Projected images of the paintings, original felt installations and costumes design, graphic art, original 
theatrical lighting, and a video performance piece; and (e) Documentary film - Entire trans-artistic process from development to presentation captured digitally to document the creative process as an education tool in documentary form. The project was developed at SDSU with live performances in November of 2015.

\section{Scholarship of Teaching and Learning}

In relation to the scholarship of teaching and learning, a goal of the crossdisciplinary artistic and academic collaborative project was to contribute to the lifelong development of engaged student collaborators by fostering opportunities for students to actively create and perform, as well as opportunities to work collaboratively with faculty mentors to encourage cross-disciplinary artistic endeavors. Students engaged in artistic collaborations as each of the artists in the project mentored emerging student artists as the creative process unfolded. Several faculty members in the collaboration developed research and scholarly work connected to creativity and its transforming effect on student growth and development.

Through this collaborative experience, an emergent conceptual model of artistic and academic collaboration was developed based on the experience of the collaborators and the work produced. This model incorporates aspects of artistic and scholarly collaboration as well as common collaboration themes; however, it expands on the benefits produced beyond those of the collaborators by creating a connection to students and learning.

\section{Method \& Results}

This grounded theory approach (Charmaz, 2003; Strauss \& Corbin, 1998) to a case study is interpretive in nature, as generalizability is not the main goal of this research, but rather a rich, contextual description (Geertz, 1973). This work best falls into the scholarship of teaching and learning category by Nelson (2003) of reports of particular classes. A grounded theory approach was implemented in order to review collaborative models that could be used in conjunction with this case study to construct a new theory or model.

This study was approved as exempt human subjects' research since it involved the collection or study of existing data, documents, or records recorded by the investigator in such a manner that subjects cannot be identified, directly or through identifiers linked to the subjects.

Anonymous reflective statements were gathered from participating faculty and students after the November 2015 live performances. Process validity is achieved as all information was gathered via anonymous self-reporting measurements. The participating faculty members' own impressions of effectiveness are often considered sufficient assessment through validity by analysis in this type of study (Riege, 2003). This is based on the faculty member's own experience and expertise in the subject area as well as the various assessment measures expected at the collegiate level. Because of this, the reflective statements from participating faculty serve as a measure of effectiveness. As with any case study, generalization of the results cannot be applied to the larger population. 


\section{Collaboration Models}

Artistic and academic. The first model developed from this experience starts out where other collaboration models end, with the collaborative process and partnership from an artistic and academic standpoint. From there, the product produced (creative and scholarly) is disseminated in a form appropriate for the product (performance, peerreviewed article, etc.) and the collaborators come together again to provide feedback and reflection on work produced. This feedback and reflection then leads to future collaborations with either the core group or new members, or a combination featuring both new and old collaborators. At this point, the cycle begins again, building off the previous collaboration. As this collaborative process grows, each point produces its own trajectory. The collaborative partnership follows a path that leads to developing a new community of practice, and the creative process follows a path that leads to artistic and overall project growth. Dissemination follows a natural path of creative scholarship and peer review, and the feedback and reflection process not only creates a new community of practice but also deep and meaningful collegial relationships (Figure 5).

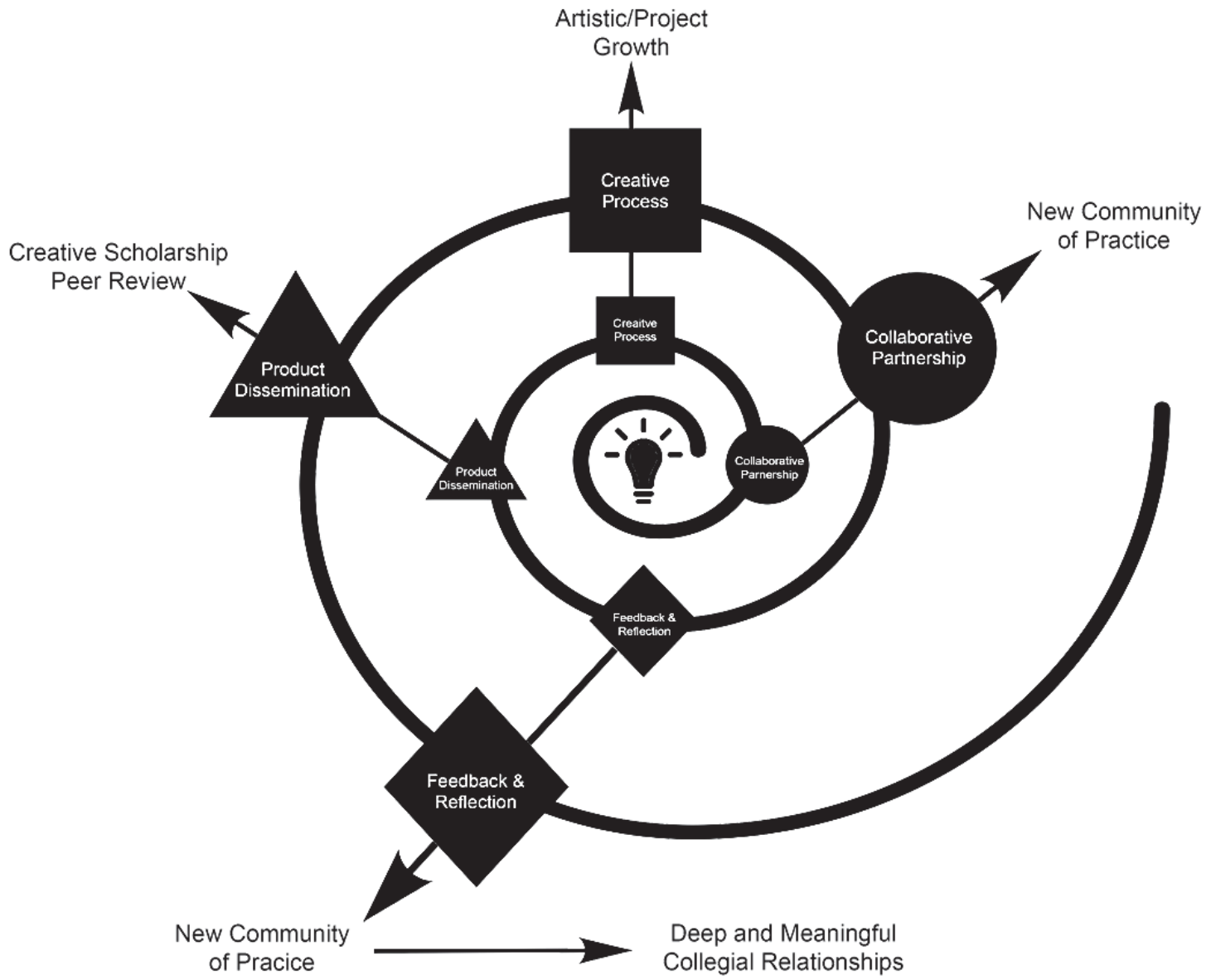

Figure 5. Artistic \& Academic Collaboration Model

Student and faculty. An important aspect of the collaborative partnership model is the opportunity for student engagement and experiential teaching and learning. This cycle follows closely to the parent model, with the added processes of 
student engagement, shared perspectives, and mentorship. This cycle grows in a similar fashion as the parent model while following a path to experiential teaching and learning and student engagement research (Figure 6).

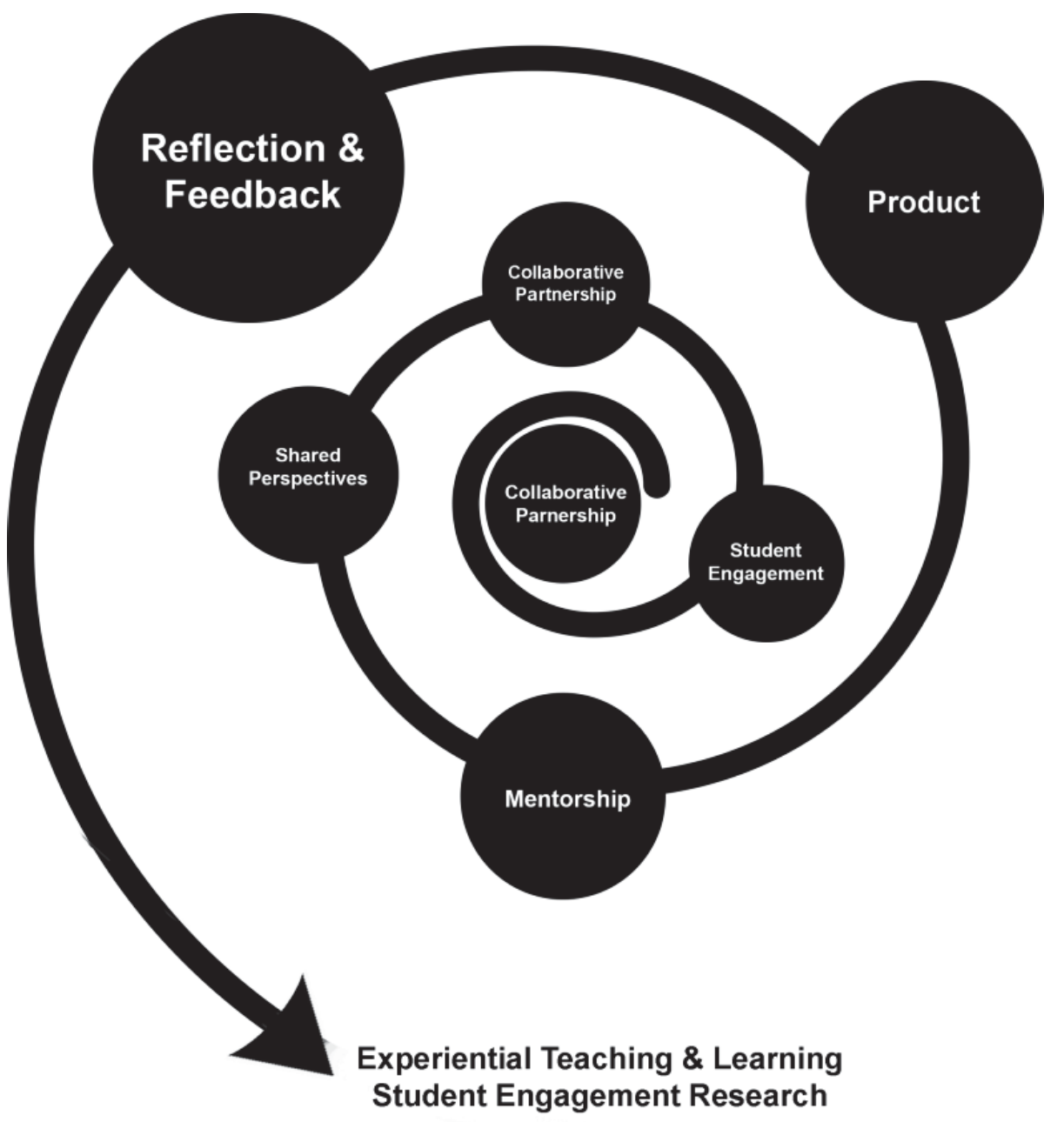

Figure 6. Student \& Faculty Engagement Model

Reflective critique. Members of the collaborative were solicited for openended comments on their overall experience and how it related to the collaborative models developed as a form of assessment through validity by analysis (Riege, 2003). This solicitation was administered using a Web-based survey tool that only collaborative members had access to. The one word used most often to describe the process was "organic." As one collaborator stated, "Many people with a variety of ideas create the need to be humble, open, receptive, and flexible. As the collaborators have grown as professionals together, we have learned to risk, trust, practice gratitude, and be open to possibility." The organic nature did create some challenges among collaborative members. As one collaborator stated:

(It) felt as if no one person within the collaborative was driving the project toward any specific goal. Though this was exciting for some, there was unease with the process for others... as the project rambled, unraveled, and re-invented itself through a variety of iterations over the years. 
All collaborators stated that the project persevered due to the trust and confidence each collaborator had with their peers. Further responses related to three main areas: (a) student mentoring and engagement, (b) the creation of scholarly or creative works, and (c) collaborative partnership and community of practice.

Student mentoring and engagement. All faculty collaborators agreed that bringing students into the collaborative process was an important and fulfilling part of the project. As one collaborator stated, "It was important to me as an educator to allow students who were particularly interested in the project due to its innovative approach to have the opportunity to participate." Student engagement was achieved both in the actual performance and in behind-the-scene roles. This provided students with a more hands-on experience. One participating faculty member elaborated on this:

I am excited that we were able to provide our student musicians with some experiential learning in a "real world" environment, including the relative permanence of committing our performance to record, and that they have taken pride in their role in the project as a whole. (Student) participation in the collaborative has provided them with opportunities to practice and enrich compositional, performance, and technical skills; as well as, participate in a community of collaborative practice that is unique and exciting.

Another faculty collaborator mentioned being able to take student engagement back into the classroom due to this project:

I have developed an ekphrasis writing project in my creative writing class. Students choose one piece of artwork in the current gallery and, over the course of the semester, complete four writing projects in response to it. They also complete a reflective piece on their writing process in response to artwork.

As this project was completed over the course of several years, reflection from students came mainly from those involved in the latest performance. All students involved in the fall 2015 performance cited the experience as being positive, with the opportunity to practice the technical skills involved in music and dance. As one student stated:

We have practiced it so many times and then getting in front of an audience it kind of brings back that passion again. Once we can really embody the movement and the poetry and the music, then I think that just makes the (performance) that much better.

Faculty collaborators also indicated a positive reaction from the student body beyond those participating in the project. As one faculty collaborator mentioned, "(Students) have told me I will now go to the art museum and witness new work 
having been to this (performance) when I wouldn't have gone to the museum otherwise."

Another faculty collaborator had a similar experience:

Students stop me in the bookstore to say I saw than and really enjoyed that, it was something I have never seen before. And the students who were involved have thanked me for doing (the project) and always ask when we are going to do something like that again.

Creation of scholarly or creative works. One collaborative model developed through this project deals with integrating scholarly or creative work into the collaborative process. Collaborators reflected on this aspect and how they have been able to achieve this:

One of the greatest benefits of the process has been the opportunity to tie my teaching/creative scholarship, research, and service into a tidy, sustainable package. The ability to do so has proven to be beneficial, effective, and efficient in terms of time management.

Another collaborator echoed this sentiment:

The project allowed me as a faculty member to focus my attentions intentionally, on sustainable exploration, creation, and research that benefits faculty, students, the community, and beyond. Truthfully, it has been the most engaging, holistic, challenging, meaningful, and rewarding experience on campus.

Collaborative partnership and community of practice. Faculty collaborators appreciated being able to work with other faculty that, under typical circumstances, they would never interact with. As one faculty member mentioned, "The interdisciplinary format of the project provided a broad and deep exploration of thematic content. An opportunity to share ideas with individuals from diverse disciplines cultivates new perspectives and avenues for creative exploration."

Another faculty member went on to state, "The opportunity to coordinate and collaborate with other faculty outside of my department on a shared creative goal was something that I needed--even if I didn't know that I needed it."

Faculty collaborators mentioned once again that crossing discipline lines was a unique and positive experience. As one collaborator stated:

In higher education we tend to work in silos surrounding our discipline and rarely get the change to draw upon the strengths of the holistic university environment. I think the level of input all members of the collaborative had on all aspects really makes the final production stronger, although it can slow down the overall process. 
Collaborative weaknesses. The challenges identified included time on task and communicating across disciplines. Collaborators mentioned needing to learn a "different language" in terms of communicating with those outside their content area. As one collaborator mentioned, "Bringing together a large group of artists, teachers, and academicians can create a certain amount of chaos. However, our ability to come together and create a true collaborative team was the highlight of this experience."

For some, dealing with the fluidness of a creative project was difficult at times; however, one collaborator stated that the final project was worth the challenges:

Each collaborator should share a PASSION for the work/project, has gifts/talents/abilities, and intellect that aligns with the project, is OPEN to AMBIGUITY, is willing to let go of their EGO, and is willing to OPEN THE DOOR even though what stands beyond looks daunting, messy, convoluted, and completely beyond their reach.

\section{Creating Communities of Practice across Disciplines}

As a case study, this research is more interpretive than generalizable; however, the hope is that these models developed through the Harvey Dunn Feminine Images Collaborative encourage educators to explore collaboration that benefits both scholarship and teaching. Previous collaborative models stop short of exploring how the work produced may foster further collaboration beyond the initial project, which is where these models pick up.

The artistic and academic model shares the work produced while also bringing the collaborators together again to provide feedback and reflection on work produced to encourage future collaborations, which spawn more collaborative work and a new community of practice.

The student and faculty model works in a similar way, yet includes aspects of student engagement, shared perspectives, and mentorship. This model works to create experiential teaching and learning pedagogy as well as student engagement research.

Faculty and students involved in the process indicated student mentoring and engagement was a key aspect at all points in the process. Being able to have one project that reached into all aspects of their role as an academic (teaching, scholarship \&

...student mentoring and engagement was a key aspect at all points in the process. creative activity, service) was a positive factor among faculty collaborators. Those involved in the project were able to see a side of other disciplines that they would have not had the opportunity do otherwise, and while that was considered an advantage, they also mentioned that learning how other faculty in other disciplines work and communicate was a challenge.

These models are collaborative in nature and therefore could be adapted to fit a combination of other disciplines. Being these models are new, there is an opportunity to apply them in other collaborative projects and see how well they function. The hope is that other institutions and faculty apply these models in their own collaborative projects to add to the community of practice as well as to test effectiveness. 


\section{References}

Alberto, J., \& Herth, K. (2009). Interprofessional collaboration within faculty roles: Teaching, service, and research. The Online Journal of Issues in Nursing, 14(2), 1-14. Retrieved from http://www.nursingworld.org/OJIN

Blom, D., Bennett, D., \& Wright, D. (2011). How artists working in academia view artistic practice as research: Implications for tertiary music education. International Journal of Music Education, 29, 1-15. doi: $10.1177 / 0255761411421088$

Borghoff, U. M., \& Schlichter, J. H. (2000). Computer-supported cooperative work: Introduction to distributed applications. Berlin, Germany: SpringerVerlag.

Burbank, M. D., \& Kauchak, D. (2003). An alternative model for professional development: Investigations into effective collaboration. Teaching and Teacher Education, 19, 499-514. doi: 10.1016/S0742-051X(03)00048-9

Candy, L., \& Edmonds, E. (2002, October). Modeling co-creativity in art and technology. In T. Kavanagh \& $\mathrm{T}$. Hewett (Program Chairs), Proceedings of the 4th Conference on Creativity $\mathcal{E}$ Cognition (pp. 134-141). New York, NY: Association for Computing Machinery. doi: $10.1145 / 581710.58173$

Charmaz, K. (2003). Grounded theory. In J. A. Smith (Ed.), Qualitative psychology: A practical guide to research methods (pp. 81110). London, Great Britain: Sage.
Deck, F. (2004). Reciprocal expertise. Third Text, 18, 617-632. doi: $10.1080 / 0952882042000285023$

Dunn, H. (1934). An evening in the classroom: Being notes taken by Miss Taylor in one of the classes of painting conducted by Harvey Dunn and printed at the instigation of Mario Cooper. Publisher Unknown. Retrieved from http://www.robolus.com/H.DunnEveningClassroom.pdf

Ellis, C. A., Gibbs, S. J., \& Rein, G. (1991). Groupware: Some issues and experiences. Communications of the ACM, 34(1), 39-58. doi: 10.1145/99977.99987

Fuks, H., Rapaso, A. B., Gerosa, M. A., \& Lucena, C. P. (2005). Appling the 3C model to groupware development. International Journal of Cooperative Information Systems, 14(2/3), 299-328. doi: 10.1142/ S0218843005001171

Geertz, C. (1973). Thick description: Toward an interpretive theory of culture. In C. Geertz (Ed.), The interpretation of cultures (pp. 3-30). New York, NY: Basic Books.

Hauschild-Mork, M. (Choreographer), Bielfeldt, D. (Writer), Ragsdale, A. (Composer), Dailey, R. (Videographer), \& Hardin, C. (Graphic Designer). (2015, November 11-15). An evening with Harvey Dunn's feminine images. Live performance in Brookings, SD. Retrieved from https://www.youtube.com/ watch?v=Vp_12fx3OUA 
Huber, M. T. (2004). Balancing acts: The scholarship of teaching and learning in academic careers. Washington, DC: American Association for Higher Education.

Jones, S. (2001). Collaboration: A threat to academic autonomy? In G. Kennedy, M. Keppell, C. McNaught, \& T. Petrovic (Eds.), Meeting at the crossroads. Proceedings of the 18th Annual Conference of the Australian Society for Computers in Learning in Tertiary Education (pp. 299-306). Melbourne: Biomedical Multimedia Unit, The University of Melbourne.

Landry, R., Traore, N., \& Godin, B. (1996). An econometric analysis of the effect of collaboration on academic research productivity. Higher Education, (3), 283. doi: 10.1007/BF00138868

Lévi-Strauss, C. (1973). Structural anthropology. Chicago, IL: University of Chicago Press.

Mamykina, L., Candy, L., \& Edmonds, E. (2002, October). Collaborative creativity. Communications of the ACM, 45(10), 96-99. doi: 10.1145/570907.570940

Mattessich, P. W., \& B. R. Monsey, B. R. (1992). Collaboration: What makes it work. St. Paul, MN: Amherst H. Wilder Foundation.

Nelson, C. (2003). Doing it: Examples of several of the different genres of the scholarship of teaching and learning. Journal on Excellence in College Teaching, 14(2\&3), 85-94. Retrieved from http://celt.muohio.edu/ject/
Neuschäfer, P. (2008). The divergence between artistic and academic dissemination of oral history: Beyond the archive-from the spoken word through performance to moving images. South African Historical Journal, 60(2), 195-208. doi: 10.1080/02582470802416419

Patel, H., Pettitt, M., \& Wilson, J. R. (2012). Factors of collaborative working: A framework for a collaboration model. Applied Ergonomics, 43, 1-26. doi: 10.1016/j.apergo.2011.04.009

Riege, A. M. (2003). Validity and reliability tests in case study research: A literature review with "hands-on" applications for each research phase. Qualitative Market Research: An International Journal, 6(2), 75-86. doi: 10.1108/13522750310470055

Ruscio, K. P. (2013). What does it mean to be a teacher-scholar? Peer Review, 15(3), 27-28. Retrieved from http://aacu.org/publicationsresearch/periodicals/Peer\%20Review

Simpson, R. L., \& Myles, B. S. (1990). The general education collaboration model: A model for successful mainstreaming. Focus On Exceptional Children, 23(4), 1-10. Retrieved from http://www.lovepublishing.com/ catalog/ focus_on_exceptional_children_31.html

Strauss, A., \& Corbin, J. M. (1998). Basics of qualitative research: Techniques and procedures for developing grounded theory (2nd ed.). Washington, DC: Sage. 
Dr. Rocky Dailey has worked as a journalist in broadcast, print and online mediums during his professional career. He received his Master's in Journalism from the University of Memphis and his Doctorate in Education from Montana State University. Dr. Dailey's academic career includes working as an adjunct at Grand Valley State University and Montana State University-Billings, and as an assistant professor in the School of Mass Communications at Virginia Commonwealth University. His professional career began at KSFY-TV as a videographer and his most recent work was as the online reporter for the Billings Gazette.

Dr. Melissa Hauschild-Mork, dancer, choreographer, studio owner/director, and educator enjoys dance and the Arts for the transformational opportunities they provide. She has participated in the Touring Artist Program and the Artist in the Schools Program for the South Dakota Arts Council. She owns Expanding Harmony Dance Studio, Directs Expanding Harmony Dance Company and Exaltation! Dance and Choral Company, and teaches dance and movement studies at South Dakota State University in Brookings, SD. She was awarded the Excellence in Teaching Award from the College of Education and Human Science in Spring 2010. 